Marketplace is provided as a service to readers using text and images from the manufacturer, supplier or distributor and does not imply endorsement by Vital. Normal and prudent research should be exercised before purchase or use of any product mentioned.

\section{Look your best}

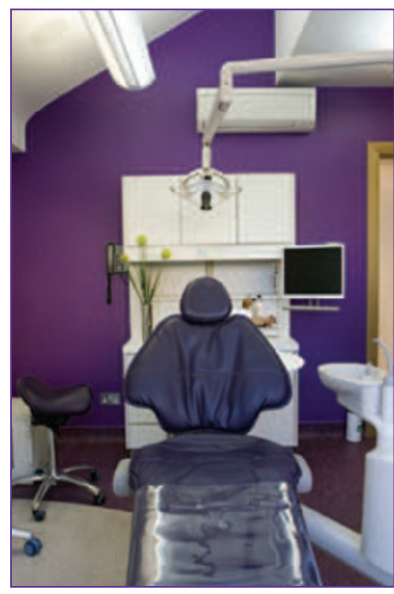

Trying to drag your dental practice into the twenty-first century? Old-fashioned décor and tired furniture? Then let Clark Dental work their magic with a total makeover.

With 30 years' experience of building and equipping surgeries, Clark Dental provides an end to end service, from design to satisfaction. Ergonomics, aesthetics, full health and safety compliance and infection control measures are all fitted as standard.

Clark Dental aim to back innovative ideas with solid experience and deliver a state-of-the-art practice which complements the quality of care you offer.

To create a professional environment that will inspire patient confidence and put a sparkle back into going to work for all your staff, contact Clark Dental on 01268733146 or clarkdental@aol.com

\section{Super stools}

Evident's DynamoSeat and InCharge stools are specifically designed with dental professionals' well-being in mind. The ergonomic design of the stools helps reduce your chances of

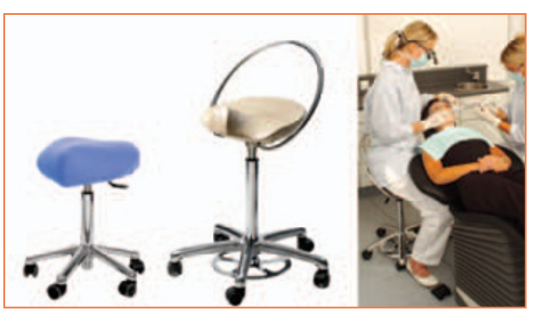
neck and back problems caused by repetitive movements. The stools automatically correct your seating position and create perfect balance, regardless of the height you're working at. They also help promote active blood circulation and improve respiration.

Good posture and the ability to work at a comfortable distance from the patient will have a positive effect on all DCPs' overall quality of life.

Evident is offering a two-week in-practice free trial of their DynamoSeat and InCharge stools. If after two weeks you've noticed a considerable difference to your overall level of comfort and performance, then on purchasing either stool you can benefit from a $15 \%$ discount on a second stool.

For more information please contact Evident on FreeCall 0500 321111 or visit www.evident.co.uk

\section{Breathing space}

If your practice is seeking to maximise efficiency and break new ground in terms of leadership, teamwork and business potential, consider a Breathe Business course for your whole team.

Breathe Business provide a complete guide to achieving your perfect dental practice, from how to energise your team and ensure that they work to their strengths, to how to manage your appointment book effectively and get the right kind of patients coming through the door.

Breathe Business was set up by two successful dentists who united to share knowledge and experience gained from coaching over 750 practices and small businesses.

Breathe Team Training enables principals and their teams to focus on every aspect of running a cutting-edge, forward-looking practice, with courses that include team-building and marketing.

Courses and training are available in Edinburgh, Manchester, Birmingham, Leeds, Bristol, London and Belfast.

For more information telephone 01326 377078, email info@ breathe.co.uk or see www.nowbreathe.co.uk.

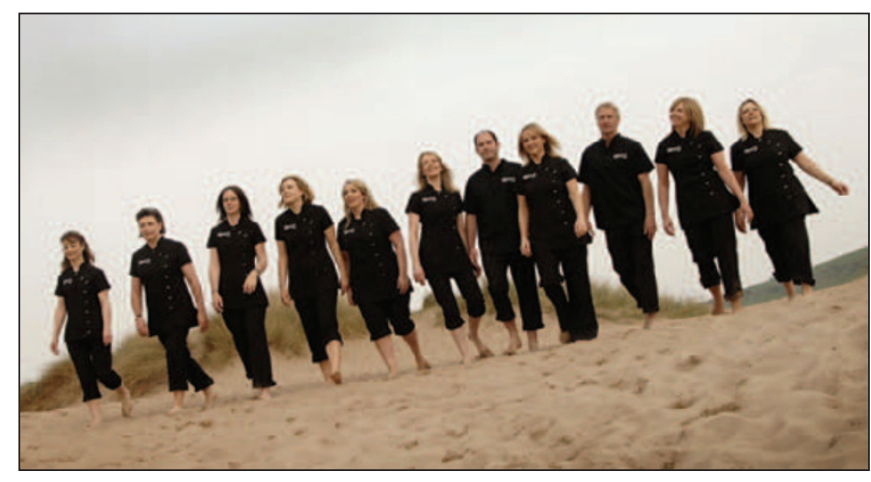

\section{Colour-changing capes}

The CollarDam ${ }^{\mathrm{TM}}$ Cape is designed to reduce the feelings of discomfort and vulnerability experienced by some patients undergoing dental treatment.

CollarDam $^{\text {TM }}$ offers not only clothing and personal protection from spillage, but also warmth. It features a combination of crystals and fibre which change colour when wet to indicate the bib should be changed - guarantee-

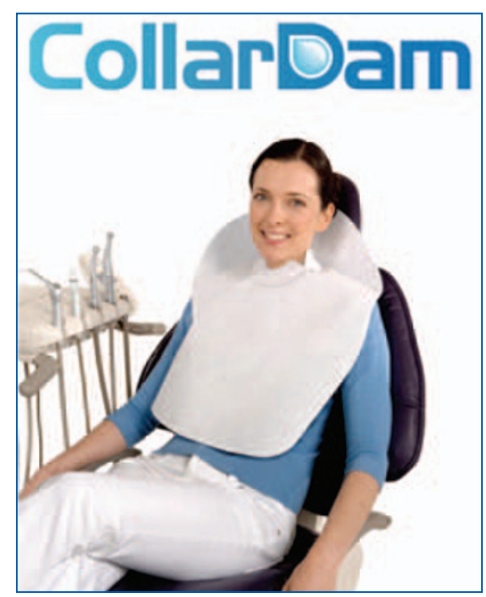

ing the patient's comfort during long periods in the dental chair.

The Cape is also one big tissue and can be used by the patient for dabbing, thereby freeing up the dental nurse's valuable time.

Professional stress is also reduced on the part of the dentist, who can be confident that the patient is as comfortable as possible.

For further information on CollarDam ${ }^{\mathrm{TM}}$, telephone 08453104286 , email collar4uk@collardam.com, or visit www.collardam.com. 